\title{
KÜRESELLEŞME VE KÜRESEL MARKALAŞMA: YERELLİK VE KÜLTÜREL GÖSTERGELER BAĞLAMINDA PRINGLES ÖRNEĞİ
}

\author{
Ömür KINAY \\ İstanbul Kültür Üniversitesi, Sanat ve Tasarım Fakültesi, İletişim Tasarımı Bölümü, İstanbul, Türkiye \\ o.kinay@iku.edu.tr
}

\begin{abstract}
It is no argument that the world has become an increasingly interactive place. This is an obvious result of globalization. In direct parallel to this, different brands have adapted their advertising strategies wherein they produced advertisements for particular countries, coded with images of their particular culture. The type of products the producers put forward and the way these products are presented to consumers in regards of cultural codes will be evaluated. This study will take into consideration a particular product of the brand Pringles, which is a globally well-known brand, and is sold all around the United Kingdom, is being analyzed. The product called Kebap the package design will be examined according to Roland Barthes's semiotic methodology, in the light of globalization and localization.
\end{abstract}

Keywords: Globalization, glocalization, branding, culture, semiology.

\section{Gİiș}

Tüm dünyada küreselleșmeyle birlikte ortadan kalkan sınırların, benzer bir kültürü ortaya çıkarması, kültürel kimliklerin yok edildiği ya da yozlaştırıldığı, benzer değer yargıları taşıyan toplumların oluşmasıyla, üreticilerin ürünlerini oluşturup satışa sunarken, hedef pazarlar konumundaki ülkelerin, kültürel değerleri göz önünde bulundurularak geliştirilen pazarlama stratejileri açısından küreselleşme kavramı, satın alma davranışlarında, önemli bir role sahip olmaktadır.

Tüketicilerin isteklerinde ülkeden ülkeye farklılık gösteren kültürel göstergelerin, pazarlama stratejilerinin ana teması olması durumu, tüketicinin satın alma davranışlarını ve ihtiyaçlarını doğrudan etkilediğinden, kültürün önemini fark etmemize sebep olmaktadır. Bu amaçlar doğrultusunda ülkelere ait kültürel göstergeleri inceleyip, pazarlama stratejilerini belirleyen küresel markalar, ürünlerini sundukları pazarlardaki ülkelerin yerel özelliklerine göre uygulamalarını geliştirmektedirler.

Bu çalışmada, Procter\&Gamble firmasına ait olan Pringles markasının, 2010 yılında Birleşik Krallık pazarında satışa sunduğu ürünü, "Kebap çeşnili Pringles" patates cipsinin, Britanya'da hangi hedef kitleye, hangi kültürel göstergeler aracılı̆̆ıyla tasarlandığının araştırması yapılacak ve adı geçen ürünün ambalajı ele alınarak, göstergebilimsel çözümlemesi üzerinde durulacaktır.

\section{KÜRESEL MARKA OLARAK PRINGLES VE YERELLEŞME SÜRECI}

Dünyada milyonlarca kişi tarafından tercih edilen, Türkiye'de de oldukça sevilen Pringles ürünleri, İngiltere'de en çok satılan atıştırmalıklar arasında yeralmaktadır. Amerikan Procter\&Gamble firması tarafindan üretildiği dönemde, üretici firma İngiltere mahkemelerine, Pringles'in patates cipsi olmadığ iddiasıyla dava açmıştır ve dava sonucunda ürünün içeriğindeki patates oranının yüzde 50'den az çıkması, haksız vergi alımı konusunu ortaya çıkarmıştır. Mahkeme yaptı̆̆ inceleme sonucu Pringles'larda yüzde 42 oranında patates ürünü olduğunu saptamış ve üründen alınan $\mathrm{KDV}^{1}$ 'nin (Value Added Tax) kalkmasına karar vermiştir (http://news.bbc.co.uk/2/hi/business/7490346.stm

\footnotetext{
${ }^{1}$ KDV: Katma Değer Vergisi
} 
06Mart2013:19:55). İngiltere kanunlarına göre, unlu mamullerden KDV alınmamas1 gerekliliğinden dolayı, verilen kararla birlikte Pringles çeşitlerinin İngiltere'deki satışı diğer ülkelere göre çok daha ucuzdur.

Ürünün o dönemdeki sahibi Procter\&Gamble firması, 2012 yılında Pringles markasını, Kellogs Şirketi'ne yaklaşık 3 milyon dolara satmıştır (http://historyofbusiness.blogspot.com, 27Mart2013/12:05).

Logo üzerinde bulunan, iri biy1klı "Julius Pringles" olarak ismi belirlenen karakterin tasarımcıs1, Louis R.Dixon'dır. (http://en.wikipedia.org, 28Mart2013/11:00) Dikey bir biçimi olan Pringles patates cipsi kutusunun tasarımcısı Amerikalı kimyager Dr.Fredric J. Baur ise 2008 yılında hayatını kaybettiğinde kendi tasarladığı Pringles kırmızı kutuya (Orijinal kutu) cesedinin küllerini koydurtmuştur (www.time.com, 28Mart2013/11:25).

Pringles, "Kebap çeşnili" patates cipsini 2010 yılında Birleşik Krallık pazarına, o dönemde sahibi olduğu firma Procter\&Gamble ve Tesco marketler zinciriyle birlikte çalışarak satışa sunmuştur.

\section{- Küresel - Yerel Kültür Etkileşimi Örneği Olarak Pringles Kebap}

Geleneksel doğu kültürüne ait bir yemek olan Kebabın oluştuğu coğrafi bölgenin dışına çıkarak Batılı bir bölgede, küreselleşmenin etkisiyle varolması ve küresel-yerel birlikteliğindeki durumuyla "döner"in Avrupa'da ya da Britanya adasındaki simgeleştirdiği anlamlar üzerinden değerlendirilmesi; elde edilen bulguların küreselleşme-yerelleşme söylemleri açısından değerlendirilmesi, Pringles'ın Kebap çeşnili ürününün Birleşik Krallık pazarında satışa sunulmasından yola çıkılarak yapılacaktır.

Bir Yunan yemeği olan Gyros ile, pişirilme esasları neredeyse aynı olan döner kebap; Yunanistan'da domuz eti ya da tavuk etiyle pişirildiğinden, Türkiye'nin Müslüman bir toplum olması sebebiyle keçi, dana ya da tavuk eti kullanılarak pişirilmesiyle tüketilmektedir. Döner, Avrupa kıtasında (Fransa, Almanya), Britanya adasında, Amerika Birleşik Devletleri'nde, çoğunlukla Türk Döneri ismiyle bilinmektedir ve satışa sunulduğu restaurantların vitrinlerinde helal yemek manasına gelen Halal Food iletisi ile Müslüman kesime öncelikle hitap eden bir yemek türü olarak hazırlanmaktadır.

Türkiye'de ise dönerek pişirilmesinden ötürü “döner" ismi verilen kebapla ilgili de 19. yüzyılda Bursa'da ilk kez yapıldığı bilgisinden bahsedilirken; 1900'lerde Selanik'te ilk kez yapıldı̆̆ı söylenmektedir.

Patates cipsinin tarihsel oluşumuna bakacak olursak; ilk kez, Saratoga adıyla bilinen cips, 1853 yılında New York'ta yapılmıştır ve kağıt inceliğinde dilimlenen patateslerin, dondurulmuş buzlu suya batırılması, ardından kızartılmış yağa atılması usulüyle pişirilmesiyle oluşturulmuştur. 1925 yılına kadar, hiç bir firma bu cipslerin satış1 için organize olmamıştır; artan satışlarla beraber mekanik, soyma, kesme, dilimleme makineleri geliştirilerek satışına başlanmıştır. 1936 yılına gelindiğinde ise, 3 milyon bussel ( 1 bussel $=$ $36,74541 \mathrm{~kg}$ ) satılan patates cipsi, 1957 y1lına gelindiğinde 394 milyon bussel tüketilmekteydi (Ralph ve Towne, 1959:53)

$\mathrm{MCG}^{2}$ sertifikası bulunan Pringles ürününde, Müslüman kesim tarafından kesinlikle alacağı düşünülerek hedef kitle sınırlandırılmıştır.

\footnotetext{
${ }^{2}$ Muslim Consumer Group: İngiltere'deki gida raporlama firmas1; domuz ve benzeri hayvanların derilerinden, kemiklerinden, iç yağlarından, kıllarından, maya ve enzimlerinden üretilen katkı maddeleri ihtiva edilmediğinin raporlandığ kuruluş.
} 
Döner'le ilgili başka bir bilgiye göre, 1980'lerin ortalarında Almanya'da dönerin Currywurst ${ }^{3}$ ile savaşından bahsedilmekte, ayrıca da döner kebabın yavaş yavaş Gyros'u raflardan kaldırdığına da değinilmektedir (Bischoff, 2010:163).

Şimdiye kadar sözü edilen bu ülkeler çokkültürlü politika uygulayan ülkelerdir ve genelde yoğun göç almış, yabancı kaynaklı nüfusun yerelleşmesiyle etniklik kazandığı toplumlardır; etniklik, biyolojik olmaktan öte kültürel değerlere yani doğduktan sonra kazanılanlara bağlı olmaktır (Erkal, 2005:148).

- Küreselleşme ve Küresel Markalaşma: Pringles Örneği

20. yüzyılın ikinci yarısından sonra hız kazanan ancak geçmişi 13. yüzyıla dayanan küreselleşme kavram1, 1980'den günümüze ekonomik, teknolojik, sosyal ve kültürel yaşamı en fazla etkileyen faktörlerin başında gelmektedir. Küreselleşmenin, pazarlama üzerindeki etkileri ise oldukça önemlidir; 21. yüzyılın başlarından itibaren pazarlamanın yeniden biçimlenmesine sebep olmuştur (Demirbağ Kaplan ve Baltacığlu, 2009:294).

Temel amacı "ayırt edicilik", "bilinirlik” olan markalaşma, tüketici ve müşteriyle kurulan duygusal ve fayda temelli ilişsi sayesinde rekabet avantajı elde etme durumudur. Markanın başarılı olabilmesi ve yönetilmesi, hedef pazardaki tüketici ve potansiyel müşterileri, güdüleri, zevkleri, tercihleri, ihtiyaç ve beklentileri doğrultusunda tanımlanmasıyla oluşmaktadır (Alikişioğlu, 2012:125).

"Küreselleşmeyle beraber, dünya piyasalarında hızlı değişken bir rekabet söz konusudur; buna bağll olarak Pazar dinamikleri de değişmektedir [...] Firmalar artık ürüne olduğu kadar müşteriye de odaklı çalışmaktadırlar" (Ayhan, 2012:19).

Pazarlamacılar oluşturdukları küresel markalarını, küresel pazarlara sokma gayreti içinde bulunurlar ve pazarlama stratejilerinde küresel markalar ülkelerin yerel özelliklerine göre çeşitli uygulamalar gerçekleştirmektedir. Pringles kebap ürününde de küreselleşen bir ürünün yerel niteliklerle oluşturulduğu görülmektedir.

Zorlu rekabet ortamında büyük şirketler; (P\&G gibi) ürünlerinin ayakta kalabilip, piyasada varolabilmesi için yeni fikirlerin piyasada varolabilme olasılığını değerlendirmektedir; tüketici davranış ve beklentileri konusunda araştırma yapmakta ve sonunda 100 fikirle başladıkları adımlarına 2 ya da 3 fikirle devam etmektedir. Bu uzunca süreyi aştıktan sonra, seçilen ürün için gerekli olan üretim, marka, paketleme detayları belirlenmekte ve potansiyel müşterilere denetilmektedir. Ürün tüketiciden geçer not alırsa medya ve reklam çalışmalarına geçilmektedir. Sonrasında ise markalaşmada duygusallık konusu söz konusu olmaktadır." (Ayhan, 2012:20).

"Modernliğin sonuçları adlı yapıtında sosyolog Anthony Giddens, küreselleşmenin dünyanın farkl yerlerindeki yerel kimliklerin yeniden canlanması için bir neden olduğunu belirtir. Malcolm Bernard ise, kültürlerin görsel işaretler ve araçlar ile görünür bir hale geldiğini söyler [...] çağdaş toplumlarda reklamlar bu anlamda kurumsal bir yapı olarak tüketicilerin yaşam biçimlerinin deneyimlendiği, daha önceden sahip olduğu rahatllk ve birlikteliği destekleyen bir işlev yüklenir"'(Kaplan, ve Baltacığlu, 2009:374).

Küreselleşmenin sonucunda ortaya çıkartılan, 2010 yılında Pringles markasının Kebap çeşnili patates cipsi ürünü, Tesco hipermarketlerinde satışa sunulmuştur; Tesco marketlerini diğer marketlerden ayıran temel özelliklerden bazıları ise orta ve alt gelirli vatandaşlara hitap ettiği ücret politikası ya da bir alana bir bedava (buy one get one free) gibi promosyon uygulamalarının yaygın olarak kullanıldığı marketlerden olmasıdır. Ayrıca marketin müşteri

\footnotetext{
${ }^{3}$ Currywurst: Almanya'da (özellikle Berlin) yaygın olarak tüketilen, domuz etinden üretilmiş, kızarmış sosis üzerine ketçap ya da domates salçası, köri sosu serpilerek servis edilen, geleneksel bir fast food yemek türüdür.
} 
profilinde, Birleşik Krallık'ta yaşayan yabancı uyruklu, öğrenci vatandaşların varolması da önemlidir. Dolayısıyla sözü edilen ürünün hedef kitlesi önceden belirlenmiştir.

Philip Kotler'e göre pazarlama; "Üreticiyle tüketici arasındaki tüm faaliyetlerdir. Başka bir deyişle pazarlama, ürünü satabilme ve bunun devamlılı̆̆ını sağlayabilme sanatıdır”. Tüketici talebindeki değişiklikler, ürünlerin ve markaların pazarlanmasını ön plana çıkarmıştır. Markayı bir güven unsuru haline getiren pazarlamacılar, markaya bir karakter ve simge kazandırma hedefindedir. Tüketici ile marka arasında duygusal bir bağ kurulmasıyla, duygusal önermelerin ürün seçimindeki etkileri keşfedilmiştir(Ayhan, 2012:17).

"Satılmak istenen ürünün; rakiplerine göre değişik tasarıma, özelliklere, performansa, rahatlı̆̆a, sağlamlığa vb. sahip olması üründe fark yaratmayı să̆lar" (Ayhan, 2012:36). Bu nedenledir ki; Pringles özel dikey tasarımlı kutusuyla diğer cipslerden farklı ambalajı sayesinde ayrılarak ön plana çıkmaktadır.

Altan Ayhan'ın tanımına göre ambalaj; "Reklamda da rol alarak içindeki ürünün satışı için çalışmaktadır" (Ayhan, 2012:52). Pringles kutusu ambalajına bakıldığında, 1970'lerde kutu ilk hali olan kırmızı Original ismiyle satışa sunulduğunda, kutunun ağzı konserve açacağı gibi tasarlanmıştı; bir pim sayesinde açılan ambalaj, zamanla günümüzdeki şeffaf kapağın altındaki kağıdın koparılmasıyla düşük maliyetli halini almıştır. Hem sunumunun ilginçliği, hem de içinde barındırıldığı cipslerin formunu ve kırılmasını önleyici korunaklı kutusuyla, üründe fark yaratma konusuna örnek bir çalışmadır. Ürünü koruyarak tüketiciye sunan ambalaj, günümüzde oldukça önem kazanmaktadır ve tıpkı bir Coca Cola şişeşi gibi sahip olduğu karakteristik özellik sayesinde dünyanın her yerinde bilinebilir bir cips kutusu imajını yaklaşık 40 yıldır korumaktadır.

- Kültürel Gösterge Olarak Tasarlanan Kahraman Julius Pringles

"Kültür: Toplum ve sanat hakkındaki çağdaş söylemlerde en hakim ve anlaşılması güç kavramlardan biridir. Nedeni ise farklı insanlar tarafindan farkl biçimlerde kullanılmasıdır. Antropologların kültürle ilgili yüzden fazla tanım oluşturdukları bilinmektedir. [...] Birkaç tanıma bakacak olursak; "Kültür, kuşaktan kuşağa geçen, kurallara bağll, paylaşılan, simgelere dayanan, ögrenilen davranış ve inançları kapsar. Yalnızca iyi eğitimli insanlar değil herkes kültürlüdür. Homo türü, (genel anlamda) kültür kapasitesine sahiptir, fakat insanlar yetiştirildikleri farklı kültürlere göre kendine özgü kültürler içinde yaşar. Kültür, insanın dili ve simgeleri kullanma, kültürel öğrenme kapasitesine bağlıdır. Kültür geleneksel tavır ve davranışlar ve eğitim yoluyla insanlarda içselleştirilmiş davranış kurallarıyla ilgilidir"'(Berger, 2011:141).

Büyük pazardaki ürünlerin bir kahramanı bulunmaktadır; ürün için tasarlanan bu kahraman zamanla markayı temsil etmeye başlamaktadır. Örneğin Pringles'ın karakteri olan Julius Pringles 1970'lerde markanın kahramanı olarak logosunda kullanılmaya başlanmıştır, logoda bulunan kahraman, günümüze kadar beş defa değişiklik göstermiştir (http://logos.wikia.com/wiki/Pringles).

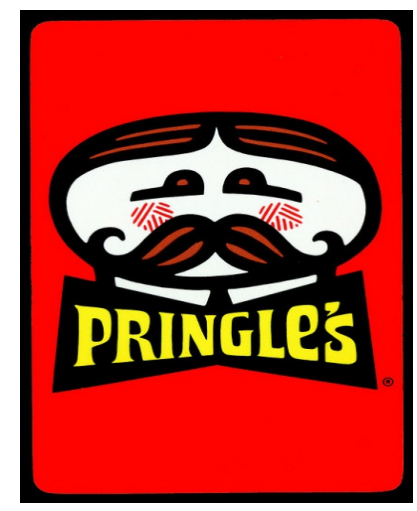

Resim1: 1970'lerdeki ilk logo (www.flickr.com). Saçları ortadan ikiye ayrılmış, kırmızı yanaklı, irice bıyıkları olan bir adam. 

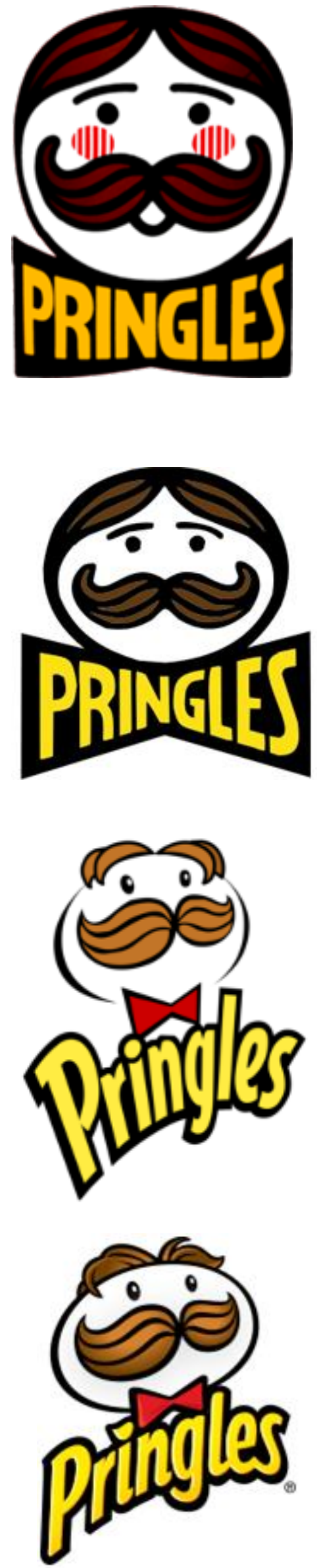

Resim2: 1986 yılında yapılan değişiklikle, tamamı büyük harflerle yazılı olan marka adındaki (Pringle's) kesme kaldırılmıştır. İlk tasarıma göre biçimsel olarak kahraman Julius Pringles'in göz biçiminde değişikliğe gidilmiş ve kaş ilave edilmiştir. Bıyı formunda da kalınlaşma söz konusudur; ayrıca kahramana dudak ilave edilmiştir. İlk logoya karşın gömlek yakası kaldırılmış ve onun yerine papyon olduğu anlaşılan ikon genişletilerek PRINGLES yazısı ön plana çıkartılmıştır.

Resim3: 1990'ların sonundaki değişiklikte ise sağlı belirtisi olan karakterin yanaklarındaki belirgin pembe yanaklar ve ağız tamamen kaldırılmış, fazla çizgilerden arındırılan logoda sadeliğe gidilmiştir. Papyon biçimi içinde vurgulanan PRINGLES yazısı boyutunda biraz daha büyüklük yapılarak isme dikkat çekilmiş yazı karakteri bir öncekiyle aynı kalmıştır.

Resim4: 2002 yılındaki değişiklikte, kaşlar kaldırılmış onun yerine kahkül biçimli saçlar ilave edilmiştir. Julius Pringles'ın bakış yönünde de bir değişiklik yapılmış; çizgiler daha rahat bir hal almıştır. En önemli değişiklik ise markanın ismi olan Pringles yazısı sadece ilk harfi büyük harfle, diğer harfler ise küçük olarak tasarlanmış ve bu defa ismin konumu papyon dışına çıkarılmış, ayrıca daha küçük boyutlarda içi kırmızı renge boyalı bir papyon karaktere ilave edilmiştir. Böylelikle form üç boyut kazanmıştır.

Resim5: Günümüzdeki halinde ise logonun kahramını Julius Pringles'ın saçındaki hareketlenme ile karaktere daha haval, hareketli bir görünüm kazandırılmıştır. Kırmızı papyon aynı konumunda bulunurken, daha dikkat çekici değişiklik markanın yazı karakterindeki Pringles'ın "i" harfinde bulunan noktasının cips biçiminde oluşturulması ve yazı karakterinin keskin hatlarından sıyrılarak daha yumuşatılmış bir hale dönüştürülmesidir. Logo üzerinde zamanla yapılmış bu değişikliklerle marka, daha çağdaş ve yalın bir formla tüketiciye sunulmuştur.

ÇÖZÜMLEME

Copyright (C) The Turkish Online Journal of Design, Art and Communication 
Çalışmada göstergebilimsel çözümleme yöntemi temel alınarak, Roland Barthes'in çözümleme ilkeleriyle Pringles patates cipsinin, Britanya'da tüketiciye sunulduğu Kebap çeşnili ürününün görseli ve Pringles markasının karakter logoları incelenmektedir. Göstergebilim, gösterge dizgelerini inceleyen bilim dalı olarak tanımlanmaktadır. Göstergebilim alanında geliştirilen yöntemlerle reklam dili çözümlemesi yapılmaktadır. Görüntünün sözbilimi üzerine ilk kez 1964 yılında çalışma yapan kişi ise Roland Barthes’tır.

Reklam üzerine yapılan çözümlemeler, reklamların anlamlarının anlaşılmasında, tüketicilere yön verilmesinde oldukça önemli bir rol oynamaktadır. Gösterge ile neye vurgu yapılmak isteniyorsa onun ön plana çıkarılması sağlanmaktadır. Barthes, 1964'te yayımlanan Rhétorique de l'image adlı yazısında resmi incelerken, şu soruları sormuştur: Resim bir dizge oluşturabilir mi? Yoksa yan yana dizilmiş simgeler olarak mı kalır? Resim nasıl anlam kazanır yani nasıl okunur? (Akerson, 2005:184).

$\mathrm{Bu}$ ilkeler doğrultusunda Pringles reklamı incelenecektir.

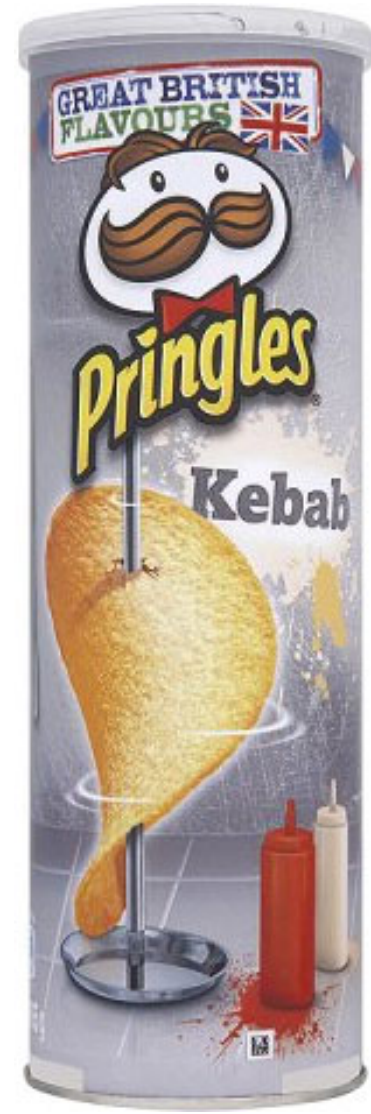

Resim6: Pringles (Kebap) Ambalaj1

Barthes'a göre, reklamın iletisi üç düzlemden oluşmaktadır:

I. Dilsel ileti; (Great British Flavours);

II. Şifrelenmemiş görüntüsel ileti (gerçeğe benzerlik);

III. Şifrelenmiş görüntüsel ileti (simgesel);

Beyaz fon üstünde, markanın "Julius Pringles" adamından oluşan logosu bulunmaktadır. Döner Kebabın takılı olduğu pişirme düzeneği, döner yerine Pringles patates cipsi, ketçap ve mayonez tüpleri bulunmaktadır. Cipsin etrafinda da dönmeyi temsil eden görsel çizim ifadesi bulunmaktadır.

Birinci ileti düzleminin; slogan, marka adı ve ürün çeşidinden (kebap) oluştuğu görülmektedir, dolayısıyla da dilsel (sözel) olduğu söylenebilir. Dilsel şifreyi çözebilmek için İngilizce okuma yazma bilmek (öğrenmiş olmak) gerekmektedir. Pringles sözcügünün anlamı marka adı olmasından ibaret değil, marka adı olarak düzanlam katında kalmaktadır. Sloganda "Great British Flavours" Büyük Britanyalı ve Muhteşem Britanyalı seçimiyle çift anlamlı bir kullanım görülmektedir. Bu anlamı destekleyici olarak da Birleşik Krallık bayrağı bulundurulmaktadır.

İkinci ileti düzleminde olan şifrelenmemiş görüntüsel ileti düzleminde ise reklamda görüp de hemen tanıdığımız şeyler bulunmaktadır: döner şişi (vertical spit), patates cipsi, ketçap ve mayonez tüpü... $\mathrm{Bu}$ nesnelerin görüntüleri asıllarına benzemektedir; yani uzlaşılmış, nedensiz göstergeler değil, yaşam deneyimlerimizden tanıdı̆̆ımız nesneleri aynen yansıtmaktadırlar. Bu ilk okumada resmin, resim olduğunu anlamak ve resimde görüleni tanımak yetmektedir. Resimdeki döner pişirme aletini tanımak bir şifre bilgisi gerektirmemektedir; bu sebeple Barthes şifrelenmemiş olarak kabul etmektedir. Bu nesnelerin resimdeki düzeni de önemlidir ancak Barthes'a göre, dildeki sözdizim anlamında şifrelenme sayılmamaktadır. Önceden belirlenmiş kesinleyici kurallar yoktur. Bu düzlem reklamda düzanlam katında bulunmaktadır.

Barthes, şifrelenmiş görüntüsel ileti düzlemini yananlam katı olarak değerlendirmekte, tek tek göstergelere ayırmakta ve bunları kültürel artalan açısından yorumlamaktadır.

"Yananlam, bir terime ve geniş anlamda bir imgeye, bir metindeki figüre hatta bir metne eklenen kültürel anlamı ifade etmek için kullanılan bir terimdir. Karşıt olarak kullanılan düzanlam ise bir terimin, figürün, metnin vb. gerçek anlamını ifade” etmektedir (Berger, 2012:92). 
Gösterge 1:

Gösteren: Patates Cipsi Kutusu

Gösterilen: Kebap çeşnili olduğu anlaşılan patates cipsi

Yananlam aşaması ise: Doğu kültürüne ait geleneksel yemekleri olan kebap sözcüğünün burada bunun bir "döner kebap" olduğuna gönderme yaptığı görülmektedir. Yani bu ürünü alan kişiler ürünü yerken kebap tadına varacaklarının göstergesidir.

Döner kebabın, içinde barındırdığı çeşitliliği, hamuru ve etinden dolayı ağır diye tanımladığımız ürün olan yemeğin aksine bir adet patates cipsi ile cipsin hafifliğine gönderme yapılmıştır.

Gösterge 2:

Gösteren: Bir adet patates cipsi

Gösterilen: Doğulular için geleneksel yemek göndermesi

Döner Kebap ile doğu çağrışımı yapılırken, "Muhteşem Britanya lezzeti" iletisi ile dilsel

düzlemde zıtlaşmaktadır. Ürün İngiltere pazarında, İngiltere'de yaşayan

Doğulu/Arap/Türk/Müslüman kesim için görsel göstergeler açısından daha anlamlı olacaktır ancak söz konusu aynı ürün Türkiye pazarında satışa çıkarılsaydı aynı değeri/ilgiliyi göremeyebilirdi.

Gösterge 3:

Gösteren: Nesnelerin seçimi

Gösterilen: Bir araya getirilen bu nesneler (döner şişi, ketçap, mayonez) kebabı yerken tatlandırılan her şeyin burada bulunduğunu göstermeye yöneliktir. Çünkü İngiltere'de kebap restaurantlarında genellikle kebap çeşitleri ketçap ve mayonez ile servis edilmektedir; sebebi ise fast food alışkanlığından gelmektedir, Türk, Arap ya da doğu mutfağından yemek yiyen Britanyalı ya da Avrupalılar genellikle yemeklerini ketçap, mayonez ve sarımsaklı sos ile tatlandırarak tüketmektedirler bu da doğu yemeğinin batılılaşmış halidir.

Gösterge 4:

Gösteren: Resmin tümü

Gösterilen: Doğu - Batı kültürleri

Bu reklam, geleneksel Doğu yemeği olan kebabı çağrıştırmaktadır.

Doğu kültürüne ait olan bu geleneksel yemeğin genel adı olan Kebap (isim-Arapça), TDK sözlüğünde "Doğrudan doğruya ateşte veya kap içinde susuz olarak pişirilmiş et" anlamında belirtilmektedir. Et manasında da kullanılan kebap, doğu mutfağı kültürünün yemeklerinin başlıca ürünü olmasından kaynaklı etli ve hamurlu yemeklerin genel adıdır (tdk.gov.tr).

Patates cipsi ise; "çok ince doğranmış patateslerin kırılgan hale gelene kadar yağda kızartılmaslyla oluşmuş bir yiyecektir. Temelde ürün kizartılır ve tuzlanır; ancak çeşitli baharatlarla, peynirlerle, bitkisel katkılarla ya da doğala özdeş aromalar ile hazırlanan pek çok çeşidi bulunur. Atıştırmalık bir gıda" olarak tanımlanmaktadır (tr.wikipedia).

Her ikisi de fast food yani hızlı yemek kategorisinde sayılabilen ürünler; geleneksel ve otantik yiyecek olan kebabın Batılılık ve çağdaşlığa vurgu yapan imgelerle paketlenmesi örneğini göstermektedir. Görüntülerin aslında şifrelenmiş olduğunu gördüğümüz bu görüntüsel ileti düzleminde, Döner Kebap makinasını belli bir kültür şifresi içinde, başka bir değerle alımlıyoruz. Şifrenin bu şekilde çözümlenmesinin sebebi ise; bu göstergelerin değerleri üstünde Doğu kültürüne ait uzlaşılmış, yani şifrelenmiş görüntüsel göstergeler olarak karşımıza çıkmalarıdır.

Britanya'da Doğu kültürüne ait yemeklerin; şiş kebap, döner kebap, pide, lahmacun vb. sunulduğu restaurantların artışındaki en büyük etken Britanya'nın aldığı göçtür, bu kültürü benimseyen Britanyalılar da zamanla kültürün bir parçası halini almışlardır. Ve bu yemeklerin hazırlanışı ve tüketimindeki hız bunda önemli bir rol oynamıştır. Pringles markası ürünü olan 
cips de atıştırmalık (snack)bir ürün olarak, hızlı yemek (fast food) kategorisindeki ürünle bir araraya gelmiştir.

Yine çözümlemeye dönüldüğünde, bu üç düzlemin birbiriyle etkileşim içinde oldukları söylenebilir. Birinci düzlem, yani dilsel ve sözel olan düzlem, öteki iki düzlem açısından belirleyici olma özelliğini taşımaktadır. Daha önce de belirtildiği gibi reklamda kullanılan dilin şifresini bilmemiz gerekmektedir. Ürün sadece İngiltere pazarında satışa sunulmaktadır; inceleme için bakıldığında İngilizce bilmeyen biri tarafından dilsel iletinin şifresini çözmek güçleşecektir. Yeniden slogana bakıldığında (Great British Flavour) Britanyalı olmak ile üst anlam yüklenmektedir; "Dünyanın en büyük ekonomik gücü konumundaki, ticari ve endüstriyel gelişmenin zirvesindeki, ilk endüstrileşen ulus niteliğindeki Britanya"nın kimliğine sahip olmak ile eş değerdir.

(http://ilef.ankara.edu.tr/id/yazi.php?yad=798).

Reklamda başvurulan söz oyunlarından ya da diğer bir deyişle retorik figürlerden abartl, eğretileme, düzdeğişmece sözel alanda kullanıldı̆̆ 1 gibi, görüntüsel olarak da kullanılmaktadır.

Prof.Dr.Rengin Küçükerdoğan'ın tanımında Abartl; “Reklam iletisinde en çok ele alınan konuyu vurgulayan abartma, iletiyi yineleme yaparken tekdüzelikten koruyan eşanlamlılık, betimlemede varsıllık sağlayan dolaylama, iki karşıt sözcügün ya da düşüncenin aynı anda kullanıldığı karşıtlamı sayabiliriz” diye tanımlanmaktadır (Küçükerdoğan, 2011:148).

Resim6'daki görselde, patates cipsinin boyutu olduğundan büyük gösterilerek tüketicinin dikkatini çekmesi amaçlanmıştır. "Ĕ̆retileme, bir şeyi başka bir şey yoluyla açıklama, yorumlama ya da örnekleme ile anlam oluşturan dil mecazlarıdır" (Berger, 2012:94). Yani görseldeki benzerlik ilişkisidir; patates cipsinin döner kebaba benzemesi durumudur.

"Düzdeğişmece, anlamin örnekseme yoluyla oluştuğu eğretilemenin aksine, anlamın çağrışım yoluyla oluştuğu bir dil mecazıdır" (Berger, 2012:94). Yani parça-bütün ilişkisi kurularak, patates cipsinin kebap çağrışımı yapmasıdır.

İkinci ve üçüncü düzlemler görüntüsel düzlemlerdir; biri şifrelenmiş, biri de şifrelenmemiştir. Şifrelenmemiş alanlar görüntülerin düzanlam katıdır bir başka deyişle gördüğümüzü tanımaktan oluşmaktadır. Şifrelenmiş alan ise; bu görüntülerin yananlamları ile ilintilidir. Yananlamların kurulmasında, dönemin geçerli kültürel ve ideolojik şifrelerini de içinde bulundurmaktadır.

\section{SONUÇ}

Küreselleşmenin getirdiği sınırsızlık; marka ve ürünlerin satış-pazarlamasında, hedef kitlelere yönelik iletişim stratejilerinin ve reklam yaratım süreçlerinin belirlenmesinde önemli bir rol oynamaktadırlar.

Batıdan gelen (Batılılaşmış) ve küreselleşmenin getirdiği sınırsızlıkla yaygınlaşan ürünlerin, yerel kültürün özelliklerine göre, simgeleşen imgeleri seçerek, hedef kitlenin özellikleri göz önünde bulundurularak nasıl pazarlandığına örnek oluşturmaktadır. $\mathrm{Bu}$ stratejileri oluştururken faaliyet gösterdikleri ülkelerin kültürel göstergesi olan simgelerden faydalanılmaktadır. Örneğin; Pringles markası, küresel olan "orijinal” ürününün dışına çıkarak, yerellik etrafında satışa çıkardığı, Birleşik Krallık'a özgü, İngiltere'nin kültürel göstergelerini de içinde barındırarak, her iki özelliği; küresel (global), yerel (lokal) birleştirip, glokal olarak Pringles Kebap ürününü oluşturduğu görülmektedir. Batı Kültürü tarafindan yaratılmış Pringles Kebap patates cipsi, Birleşik Krallık'ta, Doğu kültürü tarafından benimsenmiş kebabın o ülkeye göre uyarlandığı bir ürün olarak raflardaki yerini almıştır.

Günümüzde fast food kültürünün içinde sayılabilen atıştırmalık cipsler tüm Dünya'da hızla yaygınlaşmaktadır. Çağdaş yaşamın vazgeçilmezi gibi algılanmaya başlanan bu tür ürünler; yoğun olarak gençleri, çocukları hedef alarak pazarlanmaktadırlar. Küreselleşmenin sağladığı kolaylıkla yaygınlaşan, hergün milyonlarca insan tarafından satın alınan bu ürünler, özellikle 
serbest zaman tüketiminin ayrılmaz birer elamanı gibi de konumlanmaktadır. Kültürel göstergeler aracılığıyla tasarlanan ambalajları ise satın alma davranışlarında etkili birer rol oynamaktadırlar.

\section{KAYNAKLAR}

Ayhan, Altay. "Yaşamdan Örneklerle Yedi Adımda Markalaşma", İstanbul:Sistem, 2012. Alikişioğlu, Mehmet. "Reklamın İyisi”, İstanbul:Optimist, 2012.

Akerson, Fatma. "Göstergebilime Giriş", İstanbul:Multilingual, 2005.

Berger, Arthur Asa. "Kültür Eleştirisi - Kültürel Kavramlara Giriş". Çev:Özgür Emir, İstanbul:Pinhan, 2011.

Bischoff, Eva. "Hybrid Cultures - Nervous States: Britain and Germany in a (Post) Colonial World". Der: Ulrike Lindner ve Maren Möhring ve Mark Stein ve Silke Stroh. Hollanda, 2010.

Demirbağ Kaplan, M ve T. Baltacioğlu. "Küresel Markalama Stratejileri”. N. Timur ve A. Özmen (Ed.) Stratejik Küresel Pazarlama içinde. Ankara:Eflatun, 2009.

Erkal, Mustafa. "Küreselleşme, Etniklik, Çokkültürlülük". İstanbul:Derin, 2005.

Küçükerdoğan, Rengin. "Reklam Nasıl Çözümlenir - Reklam İletişiminde Göstergeler ve Stratejiler" Beta:İstanbul, 2011.

Porges, Ralph ve Towne, W. "Sewage and Industrial Wastes" ,Water Environment:Amerika, 1959.

"pringles logo historical" http://logos.wikia.com/wiki/Pringles

“1970's pringles logo" www.flickr.com

Hall, Stuart. "Yerel ve Küresel: Küreselleşme ve Etniklik". Çev:Hakan Tuncel, http://ilef.ankara.edu.tr/id/yazi.php?yad=798 (30Mart2013/22:00)

http://en.wikipedia.org. "Pringles". (28Mart2013/11:00)

www.tdk.gov.tr "kebap". (30Mart2013/19:45)

http://tr.wikipedia.org "patates cipsi". (30Mart2013/19:50)

http://www.time.com/time/business/article/0,8599,1811730,00.html. (28Mart2013/11:25)

http://historyofbusiness.blogspot.com/2012/04/history-of-pringles-potato-chips.html (27Mart2013/12:05) 